\title{
Facultative Psychrophilic Bacteria Isolated from the Tropical Districts in Indonesia
}

\author{
Jiro Nishikawa, Kunihiro Matuoka and Hiroshi Iizuka \\ Department of Applied Biological Science, Science University of Tokyo, Noda 278, Japan
}

\begin{abstract}
In this study the bacteria inverstigated were 34 strains (P-1 P-34) isolated at $4 \sim 5^{\circ} \mathrm{C}$ by enrichment culture in Indonesia. These strains were divided into 7 subgroups (Group I GroupVII) from the results of cultural, morphological, temperature dependency of growth, biophysical investigations and cellular fatty acid composition. Group I includes 5 strains, of which one strain was mesophile and four strains were facultative psychrophiles. Group II includes 4 strains, which were concluded to be in the genus Sporosarcina and to have high salt concentration dependency of growth. Group III includes 2 strains, which showed rhizoid rough colony formation and were considered to be in the genus Alcaligenes or Flavobacterium. The relation with salt was considered to be interesting as a growth factor in this Group. Group IV includes 10 strains, of which only one strain was mesophile and remaining 9 strains were facultative psychrophiles. These strains were considered to be in the genus Alcaligenes or Pseudomonas. Their sources were distributed over very wide range.

Group V includes 7 strains, and Group VI includes 3 strains, all of which were considered as facultative psychrophile. Their optimum growth temperature were low $\left(4 \sim 27^{\circ} \mathrm{C}\right)$. Group VII includes 9 strains, all of which were considered to be in the genus Pseudomonas. In conclusion, there were no obligate psychrophlile and 23 strains were facultative psychrophile. In the case of Group VI and VII, the growth investigation and analyses of fatty acid composition by gas chromatography were carried out. As the results of these precise examinations, Group VI was considered to be very near to the genus Moraxella or Acinetobacter, and Group VII near to the geuns Chromobacterium or Pseudomonas. On the level of species determination, it was concluded that P-26, P-27 and P-33 were the same species near to Pseudomonas caryophylli, and P-6, P-31 and P-29 were considered as Moraxella bovis or Moraxella-Like-species.
\end{abstract}

Key words : Psychrophilic bacteria, Indonesia, taxonomy

\section{Introduction}

For the first time, from the standpoint of the global echology of microorganisms, and for production, processing and storage of food materials in Indonesia, biologists in Indonesia and Japan cooperated in the isolation works of many bacteria exsiting in the middle and eastern districts of Java Island, Madura Island and Bali Island etc. (Suhadi et al., 1977, 1979, 1979; Kaneko et al., 1979; Okasawa et al., 1980). These bacteria included halophilic, thermophilic, psychrophilic and radioresistant groups. In this study, only psychrophilic bacteria were investigated. The bacteria were enrichment cultured in Toryiptocase Soy Broth (B. B.L.), and a single colony was isolated three times on the same agar plate medium. The taxonomical characteristics and the temperature dependency of growth were investigated.

\section{Materials and Methods}

\section{Bacterial strains}

Bacteria isolated in Indonesia with enrichmentculture at $5^{\circ} \mathrm{C}$ in Nutrient broth $(\mathrm{pH} 7.2)$ were suspended in sterilizated water three times and a single colony was reisolated. The sources and 34 strains obtained are shown in Table 1. 
Table 1. Strains isolated and their sources

\begin{tabular}{|c|c|}
\hline Strain & Location and type of samples \\
\hline $\mathrm{P}-1$ & Sand, Pari Island \\
\hline $\mathrm{P}-2$ & Rice-field water, Genting village \\
\hline $\mathbf{P}-3$ & "1 \\
\hline $\mathbf{P}-4$ & Wet soil, Tapaksiring, Bali Island \\
\hline $\mathrm{P}-5$ & "1" \\
\hline $\mathrm{P}-6$ & Fresh fish, Tuban (Banjar) \\
\hline $\mathrm{P}-7$ & "1 \\
\hline $\mathrm{P}-8$ & "1 \\
\hline P-9 & Sea water, Pari Island \\
\hline$P-10$ & Mud, small river, Sapikerep village \\
\hline $\mathrm{P}-11$ & . \\
\hline $\mathrm{P}-12$ & "1 \\
\hline$P-13$ & Water, Kodalam village \\
\hline $\mathrm{P}-14$ & Algae, Lasam salt-field area \\
\hline $\mathrm{P}-15$ & " \\
\hline $\mathrm{P}-16$ & " \\
\hline $\mathrm{P}-17$ & Salted fish, Muncar (Sotong) \\
\hline $\mathrm{P}-18$ & Shell fish, Kenjeran coastal area \\
\hline P-19 & Rice field mud, mountain area $(+700 \mathrm{~m})$ \\
\hline $\mathrm{P}-20$ & Mud, village, mountain area $(+1000 \mathrm{~m})$ \\
\hline $\mathrm{P}-21$ & Fresh water fish, Gibanas (Nilem) \\
\hline $\mathrm{P}-22$ & Fresh fish, Kragan (Pungkur) \\
\hline P-23 & Shell fish, Kongsi Island \\
\hline $\mathrm{P}-24$ & "I \\
\hline $\mathrm{P}-25$ & Pindang fish, Bancar (Layang) \\
\hline P-26 & Algae, Banyupah coastal area \\
\hline $\mathrm{P}-27$ & Running water, salt field, Gresik \\
\hline $\mathrm{P}-28$ & Surface mud, salt field, Gresik \\
\hline P-29 & Salt, salt field, Batangan \\
\hline $\mathrm{P}-30$ & "1 \\
\hline$P-31$ & Emas fish, fresh fish, Cipanas \\
\hline $\mathrm{P}-32$ & Sisik, salted fish, Ngadisare \\
\hline$P-33$ & Algae, rice field, Kejajar \\
\hline $\mathrm{P}-34$ & "1 \\
\hline
\end{tabular}

\section{Methods for approximate classification}

We investigated taxonomical chraracteristics following Jitsukenho Nogeikagaku vol. 2 (Asakura Shoten 1978) and Indentification of Medical Bacteria 2nd Ed. (Cowan et al., 1974). Bacteria were precultured on Nutrient agar slant at $25^{\circ} \mathrm{C}$ for about 20 hrs. Cultural characteristcs were obser- ved in Nutrient agar and liquid media by plate, slant, static liquid and stab cultures. Morphological characteristcs were investigated with strains Nutrient slant cultured at $25^{\circ} \mathrm{C}$ for $20 \mathrm{hrs}$ and negative stained by negrosine solution. Motility chracteristics were studied by hanging drops preparation methods. Flagella stain was done by Nishizawa and Sugawara method. Gram stain was done by the modified method of Hucker. Spore formation was examined by Scheffer-Fulton method with Gram-positive strains cultured on potato agar slant medium. The temperature dependency of growth was studied with strains which were inoculated in Nutrient liquid medium by one loopfull amount of slant cultured sample above mentioed and reciprocally cultured in experimental tube at $2 \sim 3^{\circ} \mathrm{C}, 40^{\circ} \mathrm{C}$ and $45^{\circ} \mathrm{C}$ respectively. The degree of growth was measured by the decrease of transmittance at $660 \mathrm{~nm}$.

The optinum growth temperature was determined by the maximum decrease of transmittance (at $660 \mathrm{~nm}$ ). In this case, $0.2 \mathrm{ml}$ suspended samples were inoculated in L-type glass tube and cultured at $2.5 \sim 41^{\circ} \mathrm{C}$ for $12 \sim 18 \mathrm{hrs}$ in ToYo Kagaku Sangyo temperature gradient incubator Model TN-3. The biophysical characters were studied by the measurements of oxidase activity (Cytochromeoxidase test paper, Nissui), catalase activity (3\% $\mathrm{H}_{2} \mathrm{O}_{2}$ solution), acid formation from glucose and $\mathrm{O}-\mathrm{F}$ test.

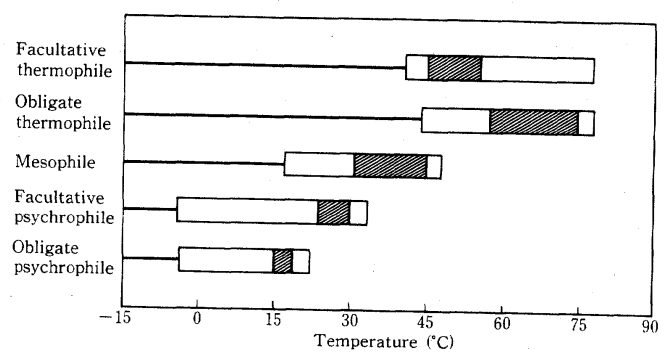

Fig. 1. Temperature ranges for multiplication of psychrophilic, mesophilic, and thermophilic bacteria. Hatched portions indicate approximate optima. (From Doetsch and Cook, 1973) 
Table 2. Cultural characteristics (1)

\begin{tabular}{|c|c|c|c|c|c|c|c|}
\hline \multirow{2}{*}{ Strain } & \multicolumn{4}{|c|}{ Nutrient agar colonies } & \multicolumn{3}{|c|}{ Nutrient agar slant } \\
\hline & Form & Color & Surface & Growth & Form & Luster & Pigment production \\
\hline $\mathrm{P}-1$ & $\mathrm{C}$ & PB & $\mathrm{S}$ & W & $\mathrm{F}$ & $\mathrm{G}$ & \\
\hline $\mathrm{P}-2$ & $\mathrm{P}$ & W & S & W & $\mathrm{F}$ & G & \\
\hline$P-3$ & $P$ & PW & $\mathrm{S}$ & W & $\mathrm{F}$ & $\mathrm{G}$ & \\
\hline $\mathrm{P}-4$ & $\mathbf{P}$ & PW & $\mathrm{R}$ & $\mathrm{G}$ & $\mathrm{F}$ & $\mathrm{D}$ & \\
\hline$P-5$ & $\mathrm{P}$ & W & $\mathrm{R}$ & $\mathrm{G}$ & $\mathrm{F}$ & $\mathrm{D}$ & \\
\hline $\mathrm{P}-6$ & $\mathrm{P}$ & MW & $\mathrm{R}$ & G & $\mathrm{F}$ & $\mathrm{G}$ & \\
\hline $\mathrm{P}-7$ & $P$ & PW & $\mathrm{S}$ & $\mathrm{G}$ & $\mathrm{F}$ & $\mathrm{G}$ & \\
\hline $\mathrm{P}-8$ & $\mathrm{C}$ & PB & S & $\mathrm{G}$ & $\mathrm{F}$ & $\mathrm{G}$ & \\
\hline P-9 & $\mathrm{C}$ & $\mathrm{O}$ & S & G & $\mathrm{F}$ & $\mathrm{G}$ & End orange \\
\hline P-10 & $\mathrm{C}$ & W & $\mathrm{R}$ & $\mathrm{G}$ & $\mathrm{F}$ & $\mathrm{G}$ & \\
\hline$P-11$ & $\mathrm{C}$ & PW & S & $\mathrm{G}$ & $\mathrm{F}$ & $\mathrm{G}$ & \\
\hline $\mathrm{P}-12$ & $\mathrm{C}$ & MW & S & G & $\mathrm{F}$ & $\mathrm{G}$ & \\
\hline $\mathrm{P}-13$ & $\mathrm{C}$ & MW & S & G & $\mathrm{F}$ & $\mathrm{G}$ & \\
\hline $\mathrm{P}-14$ & $\mathrm{P}$ & PP & $S$ & G & $\mathrm{F}$ & $\mathrm{G}$ & \\
\hline$P-15$ & $\mathrm{P}$ & $\mathrm{O}$ & $\mathrm{S}$ & $\mathrm{G}$ & $\mathrm{F}$ & $\mathrm{G}$ & End orange \\
\hline$P-16$ & $\mathrm{C}$ & $\mathrm{O}$ & S & $\mathrm{G}$ & $\mathrm{F}$ & $\mathrm{G}$ & End orange \\
\hline P-17 & $\mathrm{R}$ & PY & $\mathrm{R}$ & G & $\mathrm{F}$ & $\mathrm{G}$ & \\
\hline $\mathrm{P}-18$ & $\mathrm{C}$ & PB & S & $\mathrm{G}$ & $\mathrm{F}$ & $\mathrm{G}$ & \\
\hline P-19 & $\mathrm{R}$ & PW & S & $\mathrm{G}$ & $\mathrm{F}$ & $\mathrm{G}$ & \\
\hline P-20 & $\mathrm{C}$ & W & $\mathrm{R}$ & $\mathrm{G}$ & $\mathrm{F}$ & D & \\
\hline $\mathrm{P}-21$ & $\mathrm{C}$ & PP & S & G & $\mathrm{F}$ & $\mathrm{G}$ & \\
\hline P-22 & $\mathrm{C}$ & PB & S & $\mathrm{G}$ & $\mathrm{F}$ & $\mathrm{G}$ & \\
\hline $\mathrm{P}-23$ & $\mathrm{C}$ & PP & S & G & F & $\mathrm{G}$ & \\
\hline $\mathrm{P}-24$ & $\mathrm{C}$ & PB & S & $\mathrm{G}$ & $\mathrm{F}$ & $\mathrm{G}$ & \\
\hline $\mathrm{P}-25$ & $\mathrm{R}$ & PY & $\mathrm{R}$ & $\mathrm{G}$ & $\mathrm{F}$ & $\mathrm{G}$ & \\
\hline P-26 & $\mathrm{C}$ & PB & S & G & $\mathrm{F}$ & G & Exo brown \\
\hline $\mathrm{P}-27$ & $\mathrm{C}$ & PB & S & $\mathrm{G}$ & $\mathrm{F}$ & $\mathrm{G}$ & Exo brown \\
\hline P-28 & $\mathrm{C}$ & PB & S & $\mathrm{G}$ & $\mathrm{F}$ & $\mathrm{G}$ & \\
\hline P-29 & $\mathrm{C}$ & MW & S & $\mathrm{G}$ & $\mathrm{F}$ & $\mathrm{G}$ & \\
\hline P-30 & $\mathrm{C}$ & $\mathrm{O}$ & S & $\mathrm{G}$ & $\mathrm{F}$ & $\mathrm{G}$ & End orange \\
\hline $\mathrm{P}-31$ & $\mathrm{C}$ & MW & S & $\mathrm{G}$ & $\mathrm{F}$ & $\mathrm{G}$ & \\
\hline$P-32$ & $\mathrm{C}$ & MW & S & G & $\mathrm{F}$ & G & \\
\hline$P-33$ & $\mathrm{C}$ & PB & S & G & $\mathrm{F}$ & $\mathrm{G}$ & Exo brown \\
\hline P-34 & $\mathrm{C}$ & PB & S & G & $\mathrm{F}$ & $\mathrm{G}$ & \\
\hline
\end{tabular}

Nutrient agar colonies : $20^{\circ} \mathrm{C}, 2$ days.

From: C, circular ; $\mathrm{P}$, punctiform; R, rhizoid.

Color: PB, pale brown; W, white; PW, pale white; MW, milky white; O, orange; PP, pale pink; PY, pale yellow.

Surface: S, smooth; R, rough.

Growth: W, weak; G, good.

Nutrient agar slant: $25^{\circ} \mathrm{C}, 24-48$ hrs.

Form : F, filiform.

Luster: G, glistening; D, dull. 


\section{Methods for precise classification}

For the accurate classification Group VI and VII were selected. These Groups showed typical psychrophilic characteristics. In this paper the definition of psychrophile was according to Fig. 1 (Doetsch and Cook, 1973). In this case, growth curve, morphological experiments, observation of flagella, carbon sources for growth (Stanier et al. 1966) and many other biophysical characteristics were studied. The fatty acid compositions of the two Groups were analysed by gas chromatographical method, the precise process of which was reported by Nishimura et al. (1979).

\section{Results}

Cultural characteristics are summarized in Table 2 and 3. In Table 2, the results of Nutrient agar colonies and Nutrient agar slant are shown. In Table 3, the results of Nutrient broth and Nutrient stab culture are shown. Morphological characteristics are summarized in Table 4, the temperature dependency of growth and the optimum growth temperature are shown in Table 5. The degree of growth was divided into four transmittance range 0 $-4 \%(+), 40-70 \%(+)$, and $70-90 \%((+))$ and 90 $-100 \%(-)$.

Physiological properties are summarized in Table 6. From the above several experimental results and with the aid of the manual of Identification Medical Bacteria and Bergey's manual of Determinative Bacteriology 8th Ed. (Buchanan and Gibbons, 1974), 34 strains were divided into 7 groups as shown in Table 7, Table 8 and Table 9.

Among the 7 Groups, Group VI and Group VII were adopted as typical facultative psychrophilic bacteria and their more precise physiological characteristics are shown in Table 10. Group VI includes P-6, P-31 and P-29, and Group VII includes $\mathrm{P}-26, \mathrm{P}-27$ and $\mathrm{P}-33$.
Table 3. Cultural characteristics (2)

\begin{tabular}{|c|c|c|c|c|}
\hline \multirow{2}{*}{ Strain } & \multicolumn{3}{|c|}{ Nutrient broth } & \multirow{2}{*}{$\frac{\text { Nutrient stab }}{\text { Form }}$} \\
\hline & Surface & Turbidity & Odor & \\
\hline$P-1$ & $\mathrm{~S}$ & + & - & V \\
\hline$P-2$ & $\mathrm{~S}$ & $(+)$ & - & $\mathrm{F}$ \\
\hline$P-3$ & $\mathrm{~S}$ & $(+)$ & - & $\mathrm{F}$ \\
\hline $\mathrm{P}-4$ & $\mathrm{P}$ & $(+)$ & - & $\mathbf{P}$ \\
\hline$P-5$ & $\mathrm{P}$ & $(+)$ & - & $P$ \\
\hline P-6 & $S$ & $(+)$ & + & $P$ \\
\hline$P-7$ & $\mathrm{~S}$ & $(+)$ & + & $\mathrm{P}$ \\
\hline $\mathrm{P}-8$ & $\mathrm{~S}$ & $(+)$ & - & V \\
\hline P-9 & $\mathrm{S}$ & $(+)$ & - & $\mathrm{V}$ \\
\hline P-10 & $P$ & $(+)$ & - & $\mathrm{V}$ \\
\hline$P-11$ & $\mathrm{~S}$ & $(+)$ & - & $\mathrm{P}$ \\
\hline$P-12$ & $\mathrm{~S}$ & $(+)$ & - & V \\
\hline$P-13$ & $\mathrm{~S}$ & + & - & $\mathrm{F}$ \\
\hline P-14 & $\mathrm{R}$ & + & + & $\mathrm{F}$ \\
\hline P-15 & $\mathrm{S}$ & $(+)$ & - & $P$ \\
\hline P-16 & S & $(+)$ & - & $P$ \\
\hline P-17 & $\mathrm{S}$ & $(+)$ & + & $\mathrm{F}$ \\
\hline P-18 & $\mathbf{P}$ & $H$ & + & $\mathrm{P}$ \\
\hline P-19 & $\mathbf{R}$ & + & + & V \\
\hline P-20 & $P$ & $(+)$ & - & $\mathrm{V}$ \\
\hline P-21 & $\mathrm{R}$ & H & + & $\mathrm{P}$ \\
\hline $\mathrm{P}-22$ & $\mathrm{~S}$ & + & + & $\mathrm{F}$ \\
\hline$P-23$ & M & H & + & $\mathrm{F}$ \\
\hline P-24 & $\mathrm{S}$ & H & + & $\mathrm{F}$ \\
\hline P-25 & M & H & + & $\mathrm{F}$ \\
\hline P-26 & $\mathrm{P}$ & H & + & $P$ \\
\hline P-27 & $\mathrm{P}$ & H & + & $\mathrm{P}$ \\
\hline $\mathrm{P}-28$ & $\mathbf{R}$ & H & + & $P$ \\
\hline P-29 & $\mathbf{R}$ & + & + & $P$ \\
\hline $\mathrm{P}-30$ & $\mathrm{~S}$ & - & - & $\mathbf{P}$ \\
\hline $\mathrm{P}-31$ & $\mathrm{R}$ & + & + & $\mathrm{P}$ \\
\hline$P-32$ & $\mathrm{~S}$ & + & + & $\mathrm{P}$ \\
\hline P-33 & $\mathrm{P}$ & + & + & $\mathrm{P}$ \\
\hline P-34 & $\mathrm{P}$ & + & + & $\mathrm{F}$ \\
\hline
\end{tabular}

Nutrient broth : $25^{\circ} \mathrm{C}, 7$ days stational culture. Surface : $\mathrm{S}$, sediment ; $\mathrm{P}$, pellicle ; $\mathrm{M}$, membranous ; $\mathrm{R}$, ring.

Turbidity: \#, strong; + , moderate ; $(+)$, slight. Nutrient agar stab : $25^{\circ} \mathrm{C}, 5$ days.

Form: F, Filiform; P, papillate; V, vllous. 
Table 4. Morphological characteristics

\begin{tabular}{|c|c|c|c|c|c|c|}
\hline Strain & Form & $\operatorname{Size}(\mathrm{nm})$ & Motiity & Flagella & Gram stain & Spore \\
\hline P-1 & $\mathbf{R}$ & $0.8 \times 3-8$ & H & $P$ & - & \\
\hline$P-2$ & $\mathrm{R}$ & $0.8 \times 2-2.5$ & \# & $\mathrm{L}$ & - & \\
\hline $\mathrm{P}-3$ & $\mathbf{R}$ & $1 \times 2-2$ & \# & $\mathrm{L}$ & - & \\
\hline $\mathrm{P}-4$ & $\mathbf{R}$ & $0.8 \times 6-9$ & $(+)$ & $\mathrm{L}$ & + & - \\
\hline $\mathrm{P}-5$ & $\mathrm{R}$ & $0.8 \times 3-3.5$ & $(+)$ & - & + & - \\
\hline P-6 & DC & 1 & - & - & - & \\
\hline P-7 & $\mathrm{CR}$ & $1 \times 1.2$ & \# & $\mathrm{L}$ & - & \\
\hline P-8 & $\mathrm{R}$ & $1 \times 2-3.5$ & $(+)$ & $\mathrm{L}$ & + & - \\
\hline P-9 & $\mathrm{SC}$ & 1 & + & $S$ & + & + \\
\hline P-10 & $\mathbf{R}$ & $1 \times 6-8$ & - & - & + & + \\
\hline P-11 & $\mathrm{CR}$ & $1 \times 1.2-1.5$ & \# & $\mathrm{L}$ & - & \\
\hline $\mathrm{P}-12$ & $\mathrm{CR}$ & $1 \times 1.2-1.5$ & \# & $\mathrm{L}$ & - & \\
\hline P-13 & $\mathrm{CR}$ & $0.8 \times 1$ & H & $\mathrm{L}$ & - & \\
\hline P-14 & $\mathbf{R}$ & $1 \times 2-2.5$ & H & $\mathrm{L}$ & - & \\
\hline P-15 & $\mathrm{OC}$ & 1 & + & S & + & + \\
\hline P-16 & $\mathrm{DC}$ & 1 & + & $S$ & + & + \\
\hline P-17 & $\mathrm{R}$ & $0.4 \times 1-3$ & H & $P$ & - & \\
\hline P-18 & SR & $1 \times 1.5-2$ & H & $\mathrm{L}$ & - & \\
\hline P-19 & $\mathrm{CR}$ & $1 \times 1.2-1.5$ & H & $\mathrm{L}$ & - & \\
\hline P-20 & $R$ & $0.5 \times 3-3.5$ & $(+)$ & - & + & - \\
\hline $\mathbf{P}-21$ & $\mathrm{R}$ & $1 \times 3-3.5$ & H & M & - & \\
\hline P-22 & $\mathrm{R}$ & $1 \times 3-3.5$ & H & M & - & \\
\hline P-23 & $\mathrm{R}$ & $1 \times 1.5-2$ & H & $\mathrm{L}$ & - & \\
\hline P-24 & $\mathbf{R}$ & $1 \times 2.5-3.5$ & H & $\mathrm{L}$ & - & \\
\hline $\mathrm{P}-25$ & $\mathrm{R}$ & $0.8 \times 2-3$ & H & $\mathrm{L}$ & - & \\
\hline P-26 & $\mathrm{R}$ & $1.2 \times 1.5-3$ & H & $\mathrm{L}$ & - & \\
\hline P-27 & $R$ & $1 \times 2.5-3$ & H & $\mathrm{L}$ & - & \\
\hline P-28 & $\mathrm{R}$ & $1 \times 1.2-2$ & H & M & - & \\
\hline P-29 & $\mathrm{DC}$ & 1 & - & - & - & \\
\hline P-30 & $\mathrm{DC}$ & 1 & + & S & + & + \\
\hline P-31 & DC & 1 & - & - & - & \\
\hline P-32 & $\mathrm{R}$ & $1 \times 2-6$ & \# & $\mathrm{L}$ & - & \\
\hline P-33 & $\mathrm{R}$ & $1 \times 1.5-3$ & H & $\mathrm{L}$ & - & \\
\hline P-34 & $\mathrm{R}$ & $0.8 \times 1.5-2$ & & & & \\
\hline
\end{tabular}

Nutrient agar slant: $25^{\circ} \mathrm{C}, 20 \mathrm{hrs}$.

Form: R, rod; CR, coccoid-rod; DC, diplococcus; OC, octococcus; SC, staphylococcus.

Flagella: P, peritrichous; L, lophotrichous; $\mathrm{M}$, monotrichous ; S, single.

\section{Discussions}

The characteristics of strains included in each Group are summarized as follows.

In the case of P-4, P-5, P-8, P-10 and P-20 in
Group I were all Gram positive, (long) rod type, a little or no motile, with lophotrichous flagella or no flagella, positive in catalase activity, fermentation from glucose, no action type of O-F test, the optimum growth temperature of $28-32^{\circ} \mathrm{C}$, good 
Table 5. Optimum temperature and Growth at $2-3^{\circ} \mathrm{C}$, $40^{\circ} \mathrm{C}$ and $45^{\circ} \mathrm{C}$

\begin{tabular}{|c|c|c|c|c|}
\hline \multirow{2}{*}{ Strain } & \multirow{2}{*}{$\begin{array}{l}\text { Opt. temp } \\
\quad\left({ }^{\circ} \mathrm{C}\right)\end{array}$} & \multicolumn{3}{|c|}{ Growth at: } \\
\hline & & $2-3^{\circ} \mathrm{C}$ & $40^{\circ} \mathrm{C}$ & $45^{\circ} \mathrm{C}$ \\
\hline$P-1$ & 26 & - & $(+)$ & - \\
\hline$P-2$ & 29 & - & - & - \\
\hline$P-3$ & 28 & - & - & - \\
\hline P-4 & 28 & + & $(+)$ & - \\
\hline $\mathrm{P}-5$ & 28 & + & $(+)$ & - \\
\hline$P-6$ & 27 & + & $(+)$ & $(+)$ \\
\hline$P-7$ & 30 & - & - & - \\
\hline P-8 & 32 & + & - & - \\
\hline P-9 & 28 & - & $(+)$ & $(+)$ \\
\hline$P-10$ & 28 & + & - & - \\
\hline P-11 & 29 & $(+)$ & - & - \\
\hline P-12 & 29 & $(+)$ & - & - \\
\hline$P-13$ & 30 & - & H & $(+)$ \\
\hline P-14 & 33.5 & - & - & - \\
\hline$P-15$ & 35 & $(+)$ & - & - \\
\hline$P-16$ & 30 & $(+)$ & - & - \\
\hline P-17 & 31 & - & H & $(+)$ \\
\hline P-18 & 28 & H & - & - \\
\hline P-19 & 30 & $(+)$ & H & - \\
\hline P-20 & 29 & - & H & H \\
\hline$P-21$ & 31 & H & - & - \\
\hline $\mathrm{P}-22$ & 28 & H & $(+)$ & - \\
\hline $\mathrm{P}-23$ & 29 & H & - & - \\
\hline P-24 & 29 & $H$ & - & \\
\hline P-25 & 32 & + & $(+)$ & - \\
\hline P-26 & 23 & H & $(+)$ & - \\
\hline$P-27$ & 28 & \# & - & - \\
\hline P-28 & 25 & H & - & - \\
\hline P-29 & 27 & H & - & - \\
\hline $\mathrm{P}-30$ & 32 & + & - & - \\
\hline $\mathrm{P}-31$ & 24 & H & - & - \\
\hline P-32 & 29 & + & $(+)$ & - \\
\hline $\mathrm{P}-33$ & 26 & + & $(+)$ & - \\
\hline P-34 & 30 & H & + & - \\
\hline
\end{tabular}

Opt. temp: Nutrient broth in temperatual gradient incubator for 12-18 hrs.

Tra smitance (at $660 \mathrm{~nm}$ ): \#, 0-4\%; +, 40-70\% ; $(+), 70-90 \%$;,- 90-100\%.
Table 6. Physiological Characteristics

\begin{tabular}{|c|c|c|c|c|}
\hline Strain & Oxidase & Catalase & $\begin{array}{l}\text { Acid formation } \\
\text { from glucose }\end{array}$ & $\begin{array}{r}\mathrm{O}-\mathrm{F} \\
\text { test }\end{array}$ \\
\hline$P-1$ & - & + & - & - \\
\hline $\mathrm{P}-2$ & - & + & - & - \\
\hline $\mathrm{P}-3$ & - & + & - & - \\
\hline $\mathrm{P}-4$ & - & $H$ & - & - \\
\hline $\mathrm{P}-5$ & - & H & - & - \\
\hline$P-6$ & + & \# & - & - \\
\hline $\mathrm{P}-7$ & - & + & - & - \\
\hline $\mathbf{P}-8$ & $(+)$ & $(+)$ & - & - \\
\hline$P-9$ & - & H & - & - \\
\hline$P-10$ & - & $H$ & - & - \\
\hline $\mathrm{P}-11$ & - & H & - & - \\
\hline $\mathrm{P}-12$ & - & H & - & - \\
\hline$P-13$ & + & + & - & - \\
\hline$P-14$ & + & + & - & - \\
\hline $\mathrm{P}-15$ & - & + & - & - \\
\hline$P-16$ & - & \# & - & - \\
\hline $\mathrm{P}-17$ & + & + & - & - \\
\hline $\mathrm{P}-18$ & + & + & + & $\mathrm{O}$ \\
\hline$P-19$ & + & + & - & - \\
\hline$P-20$ & - & \# & - & - \\
\hline $\mathrm{P}-21$ & + & H & + & $\mathrm{O}$ \\
\hline P-22 & + & H & + & $\mathrm{O}$ \\
\hline $\mathrm{P}-23$ & + & + & + & $\mathrm{O}$ \\
\hline P-24 & + & H & + & $\mathrm{O}$ \\
\hline $\mathrm{P}-25$ & + & H & - & - \\
\hline$P-26$ & + & H & + & $\mathrm{O}$ \\
\hline P-27 & + & H & + & $\mathrm{O}$ \\
\hline $\mathrm{P}-28$ & + & H & + & $\mathrm{O}$ \\
\hline P-29 & + & H & $(+)$ & - \\
\hline$P-30$ & - & $H$ & - & - \\
\hline$P-31$ & + & $H$ & + & $\mathrm{O}$ \\
\hline $\mathrm{P}-32$ & - & H & + & $\mathrm{F}$ \\
\hline$P-33$ & + & $\#$ & + & $\mathrm{O}$ \\
\hline $\mathrm{P}-34$ & + & H & + & $\mathrm{O}$ \\
\hline
\end{tabular}

Symbols: \#, strong; - , good; $(+)$, weak ; - , none.

$\mathrm{O}-\mathrm{F}$ test: $\mathrm{O}$, oxidation; $\mathrm{F}$, fermentation; - no action 
Table 7. Grouping o experimented strains (1)

\begin{tabular}{|c|c|c|c|c|c|c|c|c|c|c|c|}
\hline & \multicolumn{5}{|c|}{ Group I } & \multicolumn{4}{|c|}{ Group II } & \multicolumn{2}{|c|}{ Group III* } \\
\hline & $\mathrm{P}-4$ & $P-5$ & $\mathrm{P}-8$ & $\mathrm{P}-10$ & P-20 & P-9 & $\mathrm{P}-15$ & $P-16$ & P-30 & P-17 & P-25 \\
\hline Gram reaction & + & + & + & + & + & + & + & + & + & - & - \\
\hline Morphology & $\mathrm{R}$ & $\mathrm{R}$ & $\mathrm{R}$ & $\mathrm{R}$ & $\mathrm{R}$ & $\mathrm{SC}$ & $\mathrm{OC}$ & $\mathrm{DC}$ & $\mathrm{DC}$ & $\mathrm{R}$ & $\mathbf{R}$ \\
\hline Motility & $(+)$ & $(+)$ & $(+)$ & - & $(+)$ & + & + & + & + & H & H \\
\hline Flagella & $\mathrm{L}$ & - & $\mathrm{L}$ & - & - & $\mathrm{S}$ & $\mathrm{S}$ & $\mathrm{S}$ & $\mathrm{S}$ & $\mathrm{P}$ & $\mathrm{L}$ \\
\hline Spore & - & - & - & - & - & + & + & + & + & & \\
\hline Oxidase & + & + & + & + & + & - & - & - & - & + & + \\
\hline Catalase & + & + & + & + & + & + & + & + & + & + & ++ \\
\hline Glucose, acid from & - & - & - & - & - & - & - & - & - & - & - \\
\hline $\mathrm{O}-\mathrm{F}$ test & - & - & - & - & - & - & - & - & - & - & - \\
\hline Colony color & $\mathrm{W}$ & W & PB & W & W & $\mathrm{O}$ & $\mathrm{O}$ & $\mathrm{O}$ & $\mathrm{O}$ & PY & PY \\
\hline Opt. temp. $\left({ }^{\circ} \mathrm{C}\right)$ & 28 & 28 & 32 & 28 & 29 & 28 & 35 & 30 & 32 & 31 & 32 \\
\hline \multicolumn{12}{|l|}{ Growt at: } \\
\hline $2-3^{\circ} \mathrm{C}$ & + & + & + & + & - & - & $(+)$ & $(+)$ & + & - & + \\
\hline $40^{\circ} \mathrm{C}$ & $(+)$ & $(+)$ & - & - & H & - & - & - & - & H & $(+)$ \\
\hline $45^{\circ} \mathrm{C}$ & - & - & - & - & \# & - & - & - & - & $(+)$ & - \\
\hline Sources & $\begin{array}{l}\text { wet } \\
\text { soil }\end{array}$ & $\begin{array}{l}\text { wet } \\
\text { soil }\end{array}$ & $\begin{array}{l}\text { fresh } \\
\text { fish }\end{array}$ & $\begin{array}{c}\text { mud } \\
\text { (small } \\
\text { river) }\end{array}$ & $\begin{array}{c}\text { mud } \\
(+1000 \mathrm{~m})\end{array}$ & $\begin{array}{c}\text { sea } \\
\text { water }\end{array}$ & $\begin{array}{c}\text { algae } \\
\text { (salt } \\
\text { field) }\end{array}$ & $\begin{array}{l}\text { algae } \\
\text { (salt } \\
\text { field) }\end{array}$ & $\begin{array}{l}\text { salt } \\
\text { (slat } \\
\text { field) }\end{array}$ & $\begin{array}{l}\text { salted } \\
\text { fish }\end{array}$ & $\begin{array}{l}\text { Pindang } \\
\text { fish }\end{array}$ \\
\hline
\end{tabular}

Morphology: R, rod; CR, coccoid rod; DC, diplococcus; OC, octococcus; SC, staphylococcus.

Flagella: P, peritrichous; L, lophotrichous; $\mathrm{M}$, monotrichous; $\mathrm{S}$, single.

Colony color: PB, pale brown; W, white; PW, pale white; MW, milky white; O, orange; PP, pale pink ;

PY, pale yellow.

* Rough and rhizoid colony.

growth at $2-3^{\circ} \mathrm{C}$ excepting $\mathrm{P}-20$, a little or no growth at $40^{\circ} \mathrm{C}$ and $45^{\circ} \mathrm{C}$ excepting P-20, and all strains were from wet soil or fresh water fish.

In the case of P-9, P-15, P-16 and P-30 in Group II, all were Gram positive, diplo-or octococcus, good motile, single polar flagella, spherical spore, negative oxidase activity, positive catalase activity, no acid formation from glucose, no action type of O-F test, orange color colony, the optimum growth temperature of $28 \sim 35^{\circ} \mathrm{C}$ (a fairly wide range), no growth over $40^{\circ} \mathrm{C}$. The strains in this group were supposed very near to the genus Sporosarcina. The sources of the group were sea water or algae in salt field, which shows that salt seems to be one requirement for growth in this group.

In the case of P-17 and P-25 in Group III, both strains were Gram negative, rod type, good motile, with peritrichous or lophotrichous flagella, posi- tive in both oxidase and catalase activities, no acid formation from glucose, no action in O-F test, faint yellow, rhizoid and rough colony formation. The optimum growth temperature was $31 \sim 32^{\circ} \mathrm{C}$, and the growth at $40^{\circ} \mathrm{C}$ was a little or weak. From characteristics above mentioned, these strains were concluded to be in the genus Alcaligenes or Flavobacterium. The main source of these strains was salted fish.

P-34, P-23, P-18, P-28, P-13, P-19, P-15, P-22, P-24 and P-14 were assembled into Group IV. These strains were rod or coccoid rod, Gram negative and good motile with lophotrichous or monotrichous flagella, and were positive in both oxidase and catalase activities. 8 strains among them were oxidative and remaining 2 strains were fermentative in O-F test. The acid formation from glucose was possible in 7 strains except for P-14, 
Table 8. Grouping of experimented strains (2)

\begin{tabular}{|c|c|c|c|c|c|c|c|c|c|c|}
\hline & \multicolumn{10}{|c|}{ Group IV } \\
\hline & P-34 & P-18 & P-23 & $\mathrm{P}-28$ & $\mathrm{P}-13$ & P-19 & $P-15$ & P-22 & P-24 & $\mathrm{P}-14$ \\
\hline Gram reaction & - & - & - & - & - & - & - & - & - & - \\
\hline Morphology & $\mathbf{R}$ & $\mathbf{R}$ & $\mathbf{R}$ & $\mathrm{R}$ & CR & $\mathrm{CR}$ & $\mathrm{R}$ & $\mathbf{R}$ & $\mathrm{R}$ & $\mathbf{R}$ \\
\hline Motility & \# & H & H & H & \# & H & \# & H & \# & \# \\
\hline Flagella & M & $\mathrm{L}$ & $\mathrm{L}$ & M & $\mathrm{L}$ & L & M & M & $\mathrm{L}$ & $\mathrm{L}$ \\
\hline Oxidase & + & + & + & + & + & + & + & + & + & + \\
\hline Catalase & \# & + & + & H & + & + & \# & H & \# & + \\
\hline Glucose, acid from & + & + & + & + & - & - & + & + & + & - \\
\hline $\mathrm{O}-\mathrm{F}$ test & $\mathrm{O}$ & $\mathrm{O}$ & $\mathrm{O}$ & $\mathrm{O}$ & - & - & $\mathrm{O}$ & $\mathrm{O}$ & $\mathrm{O}$ & - \\
\hline Colony color & PB & PB & PP & PB & MW & PW & PP & PB & PB & PP \\
\hline Opt. temp. $\left({ }^{\circ} \mathrm{C}\right)$ & 30 & 28 & 29 & 25 & 30 & 30 & 31 & 28 & 29 & 33.5 \\
\hline Growth at: & & & & & & & & & & \\
\hline $2-3^{\circ} \mathrm{C}$ & \# & H & H & \# & - & $(+)$ & H & H & \# & - \\
\hline $40^{\circ} \mathrm{C}$ & + & - & - & - & H & \# & - & $(+)$ & - & - \\
\hline $45^{\circ} \mathrm{C}$ & - & - & - & - & $(+)$ & - & - & - & - & - \\
\hline Sources & $\begin{array}{l}\text { rice } \\
\text { field }\end{array}$ & $\begin{array}{l}\text { shell } \\
\text { fish }\end{array}$ & $\begin{array}{l}\text { shell } \\
\text { fish }\end{array}$ & $\begin{array}{l}\text { surface } \\
\text { mud } \\
\text { (salt } \\
\text { field) }\end{array}$ & water & $\begin{array}{l}\text { rice field } \\
\text { mud } \\
(+700 \mathrm{~m})\end{array}$ & $\begin{array}{c}\text { fresh } \\
\text { water } \\
\text { fish }\end{array}$ & $\begin{array}{l}\text { fresh } \\
\text { fish }\end{array}$ & $\begin{array}{l}\text { shell } \\
\text { fish }\end{array}$ & $\begin{array}{l}\text { algae } \\
\text { (salt } \\
\text { field) }\end{array}$ \\
\hline
\end{tabular}

Morphology: R, rod; CR, cocoid rod; DC, diplococcus; OC, octococcus; SC, staphylococcus.

Flagella : $\mathrm{P}$, peritrichous; L, lophotrichous; $\mathrm{M}$, monotrichous; $\mathrm{S}$, single.

Colony color: PB, pale brown; W, white; PW, pale white; MW, milky white; O, orange; PP, pale pink ; PY, pale yellow.

Table 9. Grouping of experimented strains (3)

\begin{tabular}{|c|c|c|c|c|c|c|c|c|c|c|c|c|c|}
\hline & \multicolumn{7}{|c|}{ Group V } & \multicolumn{3}{|c|}{ Group VI* } & \multicolumn{3}{|c|}{ Group VII } \\
\hline & P-7 & $\mathbf{P}-11$ & $P-12$ & P-1 & P-2 & $\mathrm{P}-32$ & $P-3$ & P-6 & $\mathrm{P}-31$ & P-29 & $\mathrm{P}-26$ & $P-27$ & $P-33$ \\
\hline Gram reaction & - & - & - & - & - & - & - & - & - & - & - & - & - \\
\hline Morphology & $\mathrm{CR}$ & $\mathrm{CR}$ & $\mathrm{CR}$ & $\mathbf{R}$ & $\mathrm{R}$ & $\mathbf{R}$ & $\mathbf{R}$ & $\mathrm{DC}$ & DC & DC & $\mathrm{R}$ & R & $\mathbf{R}$ \\
\hline Motility & \# & + & \# & H & \# & \# & \# & - & - & - & \# & \# & H \\
\hline Flagella & L & $\mathrm{L}$ & $\mathrm{L}$ & $\mathbf{P}$ & $\mathrm{L}$ & L & $\mathrm{L}$ & - & - & - & $\mathrm{L}$ & $\mathrm{L}$ & L \\
\hline Oxidase & - & - & - & - & - & - & - & + & + & + & + & + & + \\
\hline Catalase & + & \# & \# & + & + & \# & + & \# & H & \# & \# & H & \# \\
\hline Glucose, acid from & - & - & - & - & - & + & - & - & + & $(+)$ & + & + & + \\
\hline $\mathrm{O}-\mathrm{F}$ test & - & - & - & - & - & $\mathrm{F}$ & - & - & $\mathrm{O}$ & - & $\mathrm{O}$ & $\mathrm{O}$ & $\mathrm{O}$ \\
\hline Colony color & PW & PB & MW & PB & W & MW & PW & MW & MW & MW & PB & PB & PB \\
\hline Opt. temp. $\left({ }^{\circ} \mathrm{C}\right)$ & 30 & 29 & 29 & 26 & 29 & 29 & 28 & 27 & 24 & 27 & 23 & 28 & 26 \\
\hline \multicolumn{14}{|l|}{ Growth at: } \\
\hline $2-3^{\circ} \mathrm{C}$ & - & $(+)$ & $(+)$ & - & - & + & - & + & \# & \# & H & - & + \\
\hline $40^{\circ} \mathrm{C}$ & - & - & - & $(+)$ & - & $(+)$ & - & $(+)$ & - & - & $(+)$ & - & $(+)$ \\
\hline $45^{\circ} \mathrm{C}$ & - & - & - & - & - & - & - & - & - & - & - & - & - \\
\hline Sources & $\begin{array}{l}\text { fresh } \\
\text { fish }\end{array}$ & $\underset{\text { (river) }}{\operatorname{mud}}$ & $\begin{array}{l}\text { mud } \\
\text { (river) }\end{array}$ & sand & $\begin{array}{l}\text { rice } \\
\text { field } \\
\text { water }\end{array}$ & $\begin{array}{l}\text { salted } \\
\text { fish } \\
\text { (Sisik) }\end{array}$ & $\begin{array}{l}\text { rice } \\
\text { field } \\
\text { water }\end{array}$ & $\begin{array}{l}\text { fresh } \\
\text { fish }\end{array}$ & $\begin{array}{c}\text { fresh } \\
\text { fish } \\
\text { (Emas } \\
\text { fish) }\end{array}$ & $\begin{array}{c}\text { salt } \\
\text { (salt } \\
\text { field) }\end{array}$ & $\begin{array}{c}\text { algae } \\
\text { (coastal } \\
\text { area) }\end{array}$ & $\begin{array}{c}\text { running } \\
\text { wate } \\
\text { (salt } \\
\text { field) }\end{array}$ & $\begin{array}{l}\text { algae } \\
\text { (rice } \\
\text { field) }\end{array}$ \\
\hline
\end{tabular}

Morphology : R, rod ; CR, coccoid rod; DC, diplococcus; OC, octococcus; SC, staphylococcus.

Flagella: P, peritrichous ; L, lophotrichous; $\mathrm{M}$, monotrichous ; S, single.

Colony color : PB, pale brown; W, white; PW, pale white; MW, milky white ; O, orange ; PP, pale pink ;

PY, pale yellow.

* Diffusible brown pigments production 
Table 10. Physiological characteristics of Group VI and Group VII

\begin{tabular}{|c|c|c|c|c|c|c|}
\hline Strain no. & $\mathrm{P}-6$ & P-31 & $\mathrm{P}-29$ & P-26 & $\mathrm{P}-27$ & $\mathrm{P}-33$ \\
\hline Pigment production & - & - & - & + & t & \\
\hline Growth in air & + & + & + & + & + & + \\
\hline Growth under anaerobic & \pm & \pm & - & - & - & - \\
\hline Denitrification & - & $(+)$ & - & $(+)$ & $(+)$ & $(+)$ \\
\hline Nitrate reduced & - & - & - & - & - & - \\
\hline Nitrite reduced & - & - & - & - & - & - \\
\hline $\mathrm{O}-\mathrm{F}$ test $(/ \mathrm{O} /-)$ & - & $\mathrm{O}$ & - & $\mathrm{O}$ & $\mathrm{O}$ & $\mathrm{O}$ \\
\hline \multicolumn{7}{|l|}{ Acid from: } \\
\hline Glucose & - & + & + & + & + & + \\
\hline Lactose & - & - & - & - & - & - \\
\hline Maltose & - & - & - & - & - & - \\
\hline Sucrose & - & - & - & - & - & - \\
\hline Fructose & - & - & - & - & - & - \\
\hline Starch & - & - & - & - & - & - \\
\hline Xylose & $(+)$ & + & + & + & + & + \\
\hline Salicine & - & - & - & - & - & - \\
\hline Mannitol & - & - & - & - & - & - \\
\hline Trehalose & - & - & - & - & - & - \\
\hline PHB accumulation & - & + & + & + & + & + \\
\hline Growth factor requirement & - & - & - & - & - & - \\
\hline Citrate as C source & - & $(+)$ & $(+)$ & + & + & + \\
\hline Haemolysis & + & + & + & - & - & - \\
\hline $\mathrm{H}_{2} \mathrm{~S}$ & - & - & - & $(+)$ & - & $(+)$ \\
\hline Indole & - & - & - & - & - & - \\
\hline Penicillin sensitivity & + & + & + & - & - & - \\
\hline \multicolumn{7}{|l|}{ Growth: } \\
\hline $2-3^{\circ} \mathrm{C}$ & + & + & + & + & + & + \\
\hline $40^{\circ} \mathrm{C}$ & $(+)$ & - & - & $(+)$ & - & $(+)$ \\
\hline $45^{\circ} \mathrm{C}$ & - & - & - & - & - & - \\
\hline S-S agar & - & - & - & + & + & + \\
\hline MacConkey agar & - & + & + & + & + & + \\
\hline $5 \% \mathrm{NaCl}$ & + & + & + & + & + & + \\
\hline $10 \% \mathrm{NaCl}$ & + & + & + & - & - & - \\
\hline $15 \% \mathrm{NaCl}$ & - & - & + & - & - & - \\
\hline $20 \% \mathrm{NaCl}$ & - & - & - & - & - & - \\
\hline \multicolumn{7}{|l|}{ Hydrolysis : } \\
\hline Aesculin & - & - & - & - & - & - \\
\hline Starch & - & - & - & - & - & - \\
\hline Gelatin & - & - & - & - & - & - \\
\hline Casien & + & + & + & - & - & - \\
\hline Tween 80 & - & $(+)$ & $(+)$ & - & - & - \\
\hline \multicolumn{7}{|l|}{ Activity : } \\
\hline Catalase & + & + & + & + & + & + \\
\hline Oxidase & + & + & + & + & + & + \\
\hline Urease & $(+)$ & - & - & + & + & + \\
\hline Arginine dihydrolase & - & - & - & + & + & + \\
\hline Opt. temp. $\left({ }^{\circ} \mathrm{C}\right)$ & 27 & 24 & 27 & 23 & 28 & 26 \\
\hline \multicolumn{7}{|l|}{ Utilization as $C$ source : } \\
\hline $\begin{array}{l}\text { Glucose } \\
\text { D-Xylose }\end{array}$ & + & - & - & $(+)$ & $(+)$ & $(++)$ \\
\hline L-Rhamnose & + & - & - & + & + & + \\
\hline D-Ribose & \pm & - & - & + & + & + \\
\hline Levulinic acid & - & - & - & - & - & - \\
\hline Citraconic acid & - & - & - & - & - & - \\
\hline Mesaconic acid & - & - & - & - & - & - \\
\hline Meso-Tartaric acid & - & - & - & + & + & + \\
\hline D- $(-)$-Tartaric acid & - & - & - & - & - & - \\
\hline Erythritol & \pm & - & - & \pm & \pm & \pm \\
\hline Adonitol & \pm & - & - & 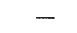 & - & - \\
\hline m-Hydroxy benzoic acid & - & - & - & - & - & - \\
\hline 2.3-Butylene glycol & \pm & - & - & + & + & + \\
\hline
\end{tabular}


Table 11. Characters of Group VI \& VII, and Gram-negative bacteria

\begin{tabular}{|c|c|c|c|c|c|c|c|c|c|c|}
\hline \multirow{2}{*}{ Strain } & \multicolumn{3}{|c|}{ Group VI } & \multirow{2}{*}{ Moraxella* } & \multirow{2}{*}{ Acinetobacter* } & \multicolumn{3}{|c|}{ Group VII } & \multirow{2}{*}{ Chromobacterium* } & \multirow{2}{*}{ Pseudomonas* } \\
\hline & $\mathrm{P}-6$ & $\mathrm{P}-31$ & P-29 & & & P-26 & $\mathrm{P}-27$ & P-33 & & \\
\hline Morphology & $\mathrm{S} / \mathrm{R}$ & $\mathrm{S} / \mathrm{R}$ & $\mathrm{S} / \mathrm{R}$ & $\mathrm{S} / \mathrm{R}$ & $\mathrm{S} / \mathrm{R}$ & $\mathrm{R}$ & $\mathbf{R}$ & $\mathrm{R}$ & $\mathrm{R}$ & $\mathrm{R}$ \\
\hline Motility & - & - & - & - & - & + & + & + & + & + \\
\hline Growth in air & + & + & + & + & + & + & + & + & + & + \\
\hline $\begin{array}{l}\text { Growth } \\
\text { anaerobically }\end{array}$ & \pm & \pm & - & - & - & - & - & - & - & + \\
\hline Catalase & + & + & + & + & + & + & + & + & + & + \\
\hline Oxidase & + & + & + & + & - & + & + & + & + & + \\
\hline $\begin{array}{l}\text { Glucose } \\
\text { (acid) }\end{array}$ & - & - & - & - & + & + & + & + & + & + \\
\hline $\begin{array}{l}\text { O-F test } \\
(\mathrm{O} / \mathrm{F} /-)\end{array}$ & - & $\mathrm{O}$ & - & - & $\mathrm{O}$ & $\mathrm{O}$ & $\mathrm{O}$ & $\mathrm{O}$ & $\mathrm{O}$ & $\mathrm{O}$ \\
\hline
\end{tabular}

* Cowan \& Steel (1974)

Table 12. Characters of Group VI, and Moraxella

\begin{tabular}{|c|c|c|c|c|c|c|}
\hline & $P-6$ & $\mathrm{P}-31$ & P-29 & $\begin{array}{c}\text { Moraxella* } \\
\text { osloensis }\end{array}$ & $\begin{array}{l}\text { Moraxella* } \\
\text { bovis }\end{array}$ & $\begin{array}{c}\text { Moraxella* } \\
\text { urethralis }\end{array}$ \\
\hline Catalase & + & + & + & + & $\mathrm{d}$ & + \\
\hline Oxidase & + & + & + & + & + & + \\
\hline $\mathrm{O}-\mathrm{F}$ test $(\mathrm{F} / \mathrm{O} /-)$ & $-3)$ & $\mathrm{o}^{2)}$ & - & - & - & - \\
\hline PHB accumulation & - & + & + & + & - & + \\
\hline Haemolysis & + & + & + & - & + & - \\
\hline Growth at $42^{\circ} \mathrm{C}$ & - & - & - & - & - & - \\
\hline Growth on nutrient broth/agar & + & + & + & + & + & + \\
\hline Serum requirement & - & - & - & - & - & - \\
\hline Growth on MacConkey & - & + & + & $\mathrm{d}^{1)}$ & - & • \\
\hline Citrate as $\mathrm{C}$ source & - & $w^{4)}$ & w & w & - & $\mathrm{d}$ \\
\hline \multicolumn{7}{|l|}{ Carbohydrates, and from: } \\
\hline glucose & - & - & - & - & - & - \\
\hline lactose & - & - & - & - & - & - \\
\hline maltose & - & - & - & - & - & - \\
\hline xylose & - & + & + & - & - & - \\
\hline Nitrate reduced & - & - & - & $\mathrm{d}$ & $\mathrm{d}$ & - \\
\hline Gelatin liquefaction & - & - & - & - & + & - \\
\hline Urease & $\mathrm{w}$ & - & - & d & - & - \\
\hline
\end{tabular}

(1) $\mathrm{d}$, Different reactions in different strains.

(2) o, Oxidation.

(3) - No action.

(4) w, Weak reaction.

* Cowan \& Steel (1974) 
Table 13. Characters of Group VII, and genus Pseudomonas

\begin{tabular}{|c|c|c|c|c|c|c|}
\hline Strain & $P-26$ & $\mathrm{P}-27$ & P-33 & P. pseudomallei* & P. caryophylli* & P. cepacia* \\
\hline No. of flagalla & $>1$ & $>1$ & $>1$ & $>1$ & $>1$ & $>1$ \\
\hline Diffusible bigments & + & + & + & - & + & + \\
\hline Arginine dihydrolase & + & + & + & + & + & - \\
\hline Denitrification & $(+)^{(1)}$ & $(+)$ & $(+)$ & + & + & + \\
\hline \multicolumn{7}{|l|}{ Hydrolysis of: } \\
\hline Starch & - & - & - & + & - & - \\
\hline Gelatin & - & - & - & + & - & $\mathrm{d}$ \\
\hline \multicolumn{7}{|l|}{ Carbon source for growth } \\
\hline Glucose & + & + & + & + & + & + \\
\hline D-Xylose & $(+)$ & $(+)$ & $(+)$ & - & $(+)$ & $\mathrm{d}$ \\
\hline D-Ribose & + & + & + & + & + & + \\
\hline L-Rhamnose & + & + & + & - & + & d \\
\hline Levulinate & - & - & - & + & - & + \\
\hline Citraconate & - & - & - & - & - & + \\
\hline Mesaconate & - & - & - & - & - & - \\
\hline D-(-)-Tartrate & - & - & - & - & - & - \\
\hline Meso-Tartrate & + & + & + & - & + & + \\
\hline Erythritol & + & + & + & + & - & - \\
\hline Adonitol & - & - & - & $\mathrm{d}^{(2)}$ & - & + \\
\hline 2.3.-Butylene glycol & + & + & + & - & + & + \\
\hline meta-Hydroxybenzoate & - & - & - & - & - & + \\
\hline
\end{tabular}

* Buchanan \& Gibbons, (1974)

(1) $(+)$, Weak reaction.

(2) $\mathrm{d}$, Different reactions in different strains.

$\mathrm{P}-13$ and $\mathrm{P}-19$. The optimum growth temperature were in the range of $25 \sim 33.5^{\circ} \mathrm{C}$. The growth tendencies were good at $2 \sim 3^{\circ} \mathrm{C}$ except for $\mathrm{P}-13$ and P-14. Over $40^{\circ} \mathrm{C}$ only P-34, P-13 and P-19 showed growth, but in the other strains a little or no growth was observed.

From the results above obtained, Group IV was considered in the genus Alcaligenes and the genus Pseudomonas. The sources were distributed widely, for example, soil, algae, crustacea and fresh water fish.

In V Group including 9 strains (P-7, P-11, P-12, P-1, P-2, P-32 and P-3), nearly all strains were Gram negative, rod or coccoid, good motile, with lophotrichous or peritrichous flagella, negative in oxidase and positive in catalase activity, acid productive from glucose and no action type in O-F test except for fementative P-32. The optimum growth temperatures were generally low (20 $\sim 30^{\circ} \mathrm{C}$ ), and the growth at $2-3^{\circ} \mathrm{C}$ were very weak or no except for P-32. The growth at $40^{\circ} \mathrm{C}$ was also weak. The sources were widely distributed (fresh water fish, river mud, sand, paddy water, salted fish). In this stage, the determination of the genus of this group is difficult and more exact study is necessary.

P-6, P-31, and P-29 strains in Group VI were Gram negative, diplococcus rod, immotile and without flagella. Both oxidase and catalase activities were positive. P-31 was oxidative and P-29 was no action type in O-F test. The optimum growth temperatures were below $27^{\circ} \mathrm{C}$, and good growth at $2 \sim 3^{\circ} \mathrm{C}$ and nearly no growth over $40^{\circ} \mathrm{C}$ were observed. The VI Group was concluded very near to the genus Moraxella-Acinetobacter.

Moraxella are compared in Table 12. In Table 
Table 14-a. Comparisons of fatty acid compositions of Group VI and Group VII with known bacteria

\begin{tabular}{|c|c|c|c|c|c|c|c|c|c|c|c|c|c|c|c|c|c|c|c|}
\hline \multirow{2}{*}{ bacteria } & \multicolumn{19}{|c|}{ straight fatty acid* (\% of total) } \\
\hline & $10: 0$ & $11: 0$ & $012: 0$ & $013: 0$ & $014: 0$ & $015: 0$ & $016: c$ & $16:$ & & $7: 0$ & $17: 1$ & $18: 0$ & $018: 1$ & $18: 2$ & $218: 3$ & $19: 0$ & $020: 0$ & $021: 0$ & $22: 0$ \\
\hline$P-6$ & 1 & & & & 2 & & 3 & 10 & & & 11 & 5 & 58 & $\mathrm{~T}$ & 1 & & & & \\
\hline P-31 & 2 & & 2 & & 2 & & 1 & 15 & & & 9 & & 56 & & & & & & \\
\hline P-29 & 2 & & 1 & & 2 & $\mathrm{~T}$ & $\mathrm{~T}$ & 12 & & & 11 & 61 & $\mathrm{~T}$ & $\mathrm{~T}$ & & & & & \\
\hline $\begin{array}{l}\text { M. bovis } \\
\text { (ATCC } \\
\text { 10900-ref.) }\end{array}$ & & & $\mathrm{T}$ & & $\mathrm{T}$ & & 4 & 26 & & $\mathrm{~T}$ & 7 & $\mathrm{~T}$ & 52 & 9 & & & & & \\
\hline $\begin{array}{l}\text { M. lacunate } \\
\text { (ATCC } \\
\text { 19975-ref.) }\end{array}$ & & & 4 & & 1 & & 15 & 14 & & $\mathrm{~T}$ & 4 & 5 & 45 & 8 & & & & & \\
\hline $\begin{array}{l}\text { M.-like-space } \\
\text { (A. } 4 \text { bby Ito 1976) }\end{array}$ & & & $\mathrm{T}$ & & $\mathrm{T}$ & & 2 & 6 & & $\mathrm{~T}$ & 14 & 1 & 61 & 3 & & & & & \\
\hline P-26 & & & 5 & & 2 & $\mathrm{~T}$ & 25 & 33 & & & & & 21 & & & & $\mathrm{~T}$ & & \\
\hline P-27 & & & 4 & & 2 & $\mathrm{~T}$ & 26 & 27 & & & & & 20 & $\mathrm{~T}$ & & & $\mathrm{~T}$ & & \\
\hline$P-33$ & & & 4 & & 2 & $\mathrm{~T}$ & 25 & 32 & & & & & 23 & & & & $\mathrm{~T}$ & $\mathrm{~T}$ & \\
\hline $\begin{array}{l}\text { Ps. aerugimosa } \\
\text { (KS 0025-ref.) }\end{array}$ & & & 3 & & 1 & 1 & 29 & 8 & & $\mathrm{~T}$ & & $\mathrm{~T}$ & 27 & & & 2 & & & \\
\hline $\begin{array}{l}\text { Ps. aeruginosa } \\
\text { (IAM } 1514 \\
\text { KSO025) }\end{array}$ & & & 7 & & 2 & $\mathrm{~T}$ & 28 & 15 & & & & $\mathrm{~T}$ & 32 & & & $\mathrm{~T}$ & & & \\
\hline $\begin{array}{l}\text { Ps. putida } \\
\text { (IAM 1506) }\end{array}$ & & & 7 & & 3 & $\mathrm{~T}$ & 35 & 12 & & & & & 11 & & & 7 & & & \\
\hline
\end{tabular}

* number before colon is carbon number, number after is unsaturation $\mathrm{T}: \leq 1 \%$

13 the same comparison as Table 12 of Group VII and the genus Pseudomonas is shown. In Table 14 the fatty acid compositions of Group VI and VII are shown. In the former, they are compared with $M$. bovis, M.lacunate (ATCC 19975, ref) and Moraxella-like-space (A-4 by Ito 1976), and in the latter, with $P$. aeruginosa (KS0025-ref.), $P$, aeruginosa (IAM1514, KS0025) and P.putida (IAM1506). The results of fatty acid composition were analyzed by the calculation of similarity value. The high similarity values $(1.00 \sim 0.99)$ were found in P-6, P-31 and P-29 (Group VI), and also the same conclusion was obtained in P-26, P-27 and P-33 (Group VII).

The formula of similarity value is as follows:

$$
\cos \phi=\frac{\sum\left(x_{i}\right)\left(y_{i}\right)}{\sqrt{\sum\left(x_{i}\right)^{2}} \cdot \sqrt{\sum\left(y_{i}\right)^{2}}}
$$

$x_{i}$ : Peak area of $\mathrm{i}$ fatty acid component of $\mathrm{X}$ strain

$\mathrm{y}_{\mathrm{i}}$ : peak area of $\mathrm{i}$ fatty acid component of $\mathrm{Y}$ strain

The characteristics of fatty acid compositions and component ratios in Group VI were high values of $\mathrm{C} 18: 1$ (56-61\%), C16:1 (10-15\%) and C17 : 1 (9-11\%), the total amount of which was 80$85 \%$.

The fatty acid compositions of the genus Moraxella were obtained by (Nishimura et al., 1979). Among these three reference species in the genus Moraxella in Table 14 very high similarity values were obtained. Moreover, the component ratios of fatty acid among Group VI and the genus Moraxella were very similar, which showed the high similarity among both groups. Group VII includes 3 strains (P-26, P-27, P-33). They are 
Table 14-b. Comparisons of fatty acid compositions of Group VI and Group VII with known bacteria

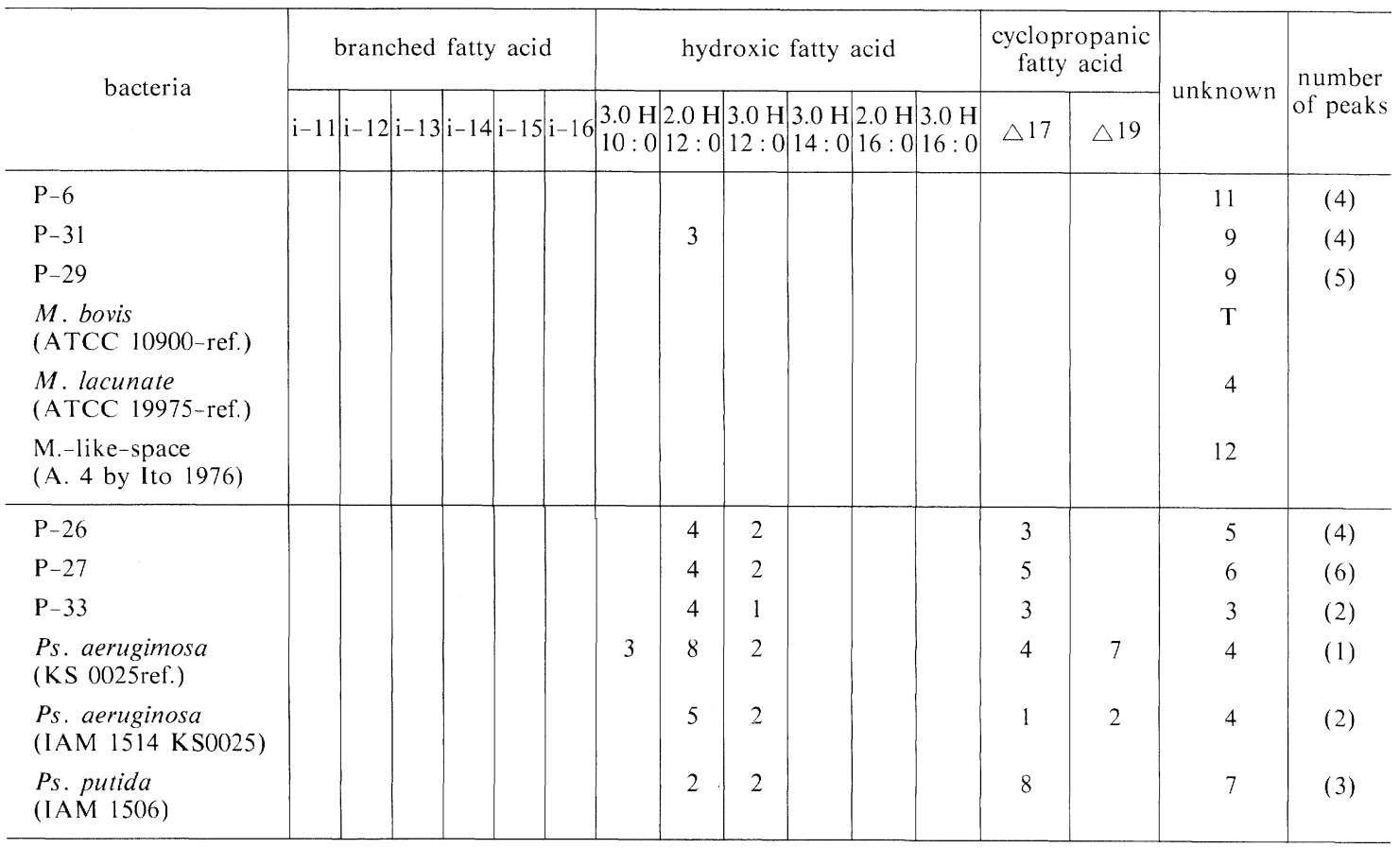

$\mathrm{i}:$ iso-brnched

$\mathrm{T}: \leq 1 \%$

Gram negative, rod, and motile with lophotrichous flagella, positive in both oxidase- and catalaseactivities, acid productive from glucose, oxidative type in O-F test. As special characteristics, they formed brown diffusible pigments at $2 \sim 3^{\circ} \mathrm{C}$. They had low optimum growth temperatures (23 $\sim 38^{\circ} \mathrm{C}$ ), and at $2 \sim 3^{\circ} \mathrm{C}$ they showed good growth. Above $40^{\circ} \mathrm{C}$, their growth were weak. The sources were algae on seashore, water in paddy-field.

In the case of Group VI and Group VII, much more detail examinations were carried out, the physiological results of which are summarized in Table 10. For the more exact examination of growth characteristics of Group VI and VII, the growth curves at $25^{\circ} \mathrm{C}$ were obtained, which are shown in Fig. 2 and 3.

From the three growth curves of Group VI, it was apparent that, P-29 and P-31 showed neary equal

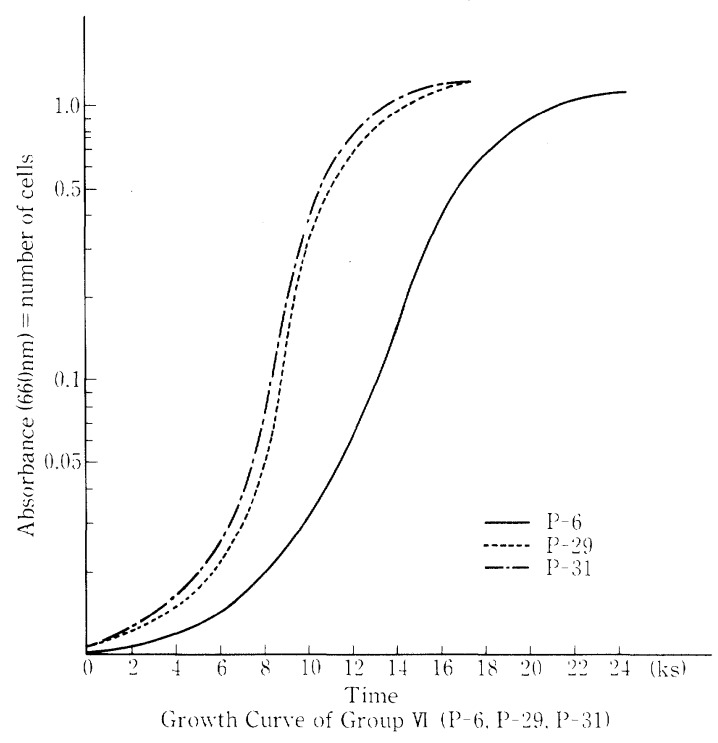

Fig. 2. Growth Curve of Group VI (P-6, P-29. P-31) 


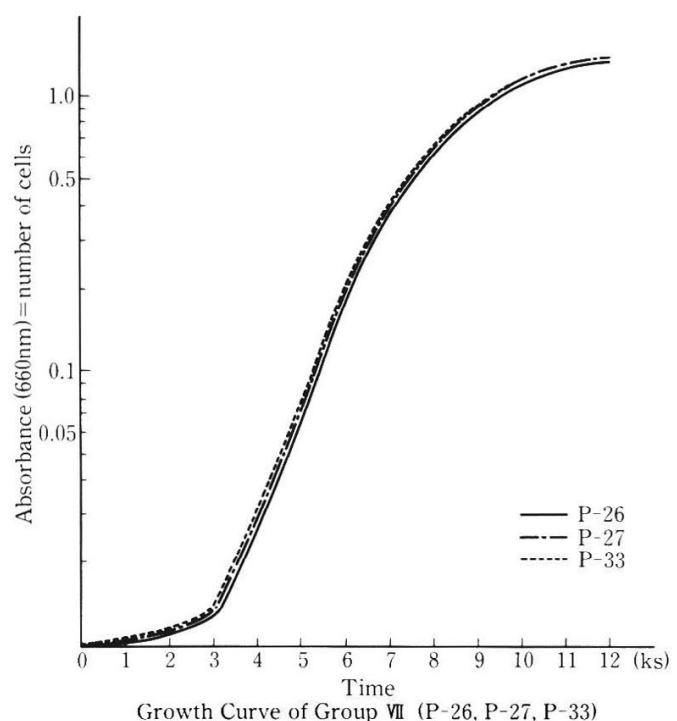

Fig. 3. Growth Curve of Group VII (P-26, P-27, P-33)

growth tendency, but P-6 was somewhat different. Fig. 3 showed that P-26, P-27 and P-33 had nearly equal curves.

In Fig. 4 the morphological change of the logarithmic and stationary growth phases of P-31 are shown, which show the change from short rod to coccoid. In Fig. 5 the cell shape of P-27 and flagella type of P-33 are shown, which are typical in the genus Pseudomonas. In Table 11 the characters of Group VI and Group VII are compared with typical gram-negative bacteria (Moraxella and Acinetobacter) and (Chromobacterium and Pseudomonas) respectively. In Table 12 the more detail characters of Group VI and three species of the genus are shown.

In the case of Group VII (P-26, P-27, P-33), the most typical characteristics were that these three strains had very high content of C16:1 (27-33\%), C16:0 (25-26\%) and C-18:1 (20-23\%), the total amount of which wwas $75-85 \%$. Moreover, it must be pointed out that the chromatograms of these three strains showed the typical pattern of genus Pseudomonas. But, however, following the report of (Ikemoto et al., 1978), the existence and

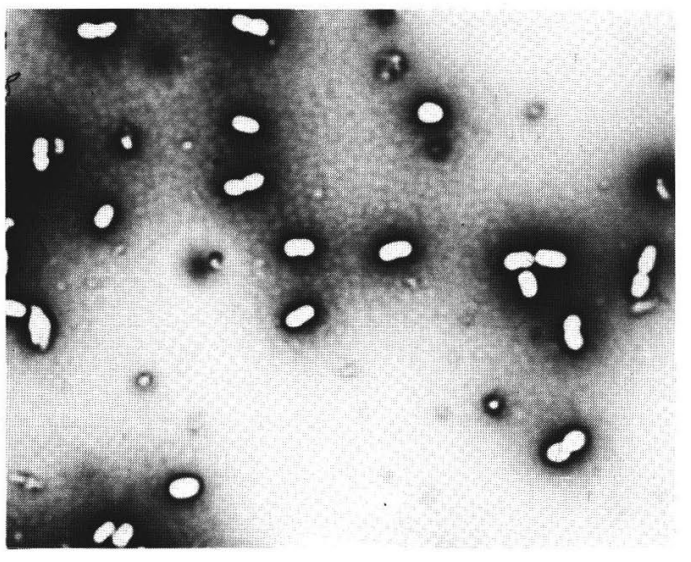

(a)

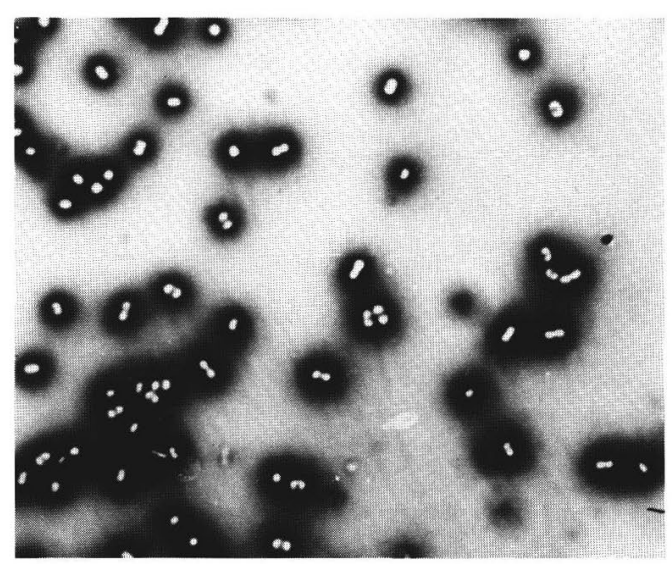

(b)

Fig. 4. Morphology of P-31 strain by negative stain (a) : early logarithmic phase. (b) : stationary phase

the ratio of typical minor fatty acid components (hydroximic acid, cyclopropanic acid, branched acid) are important factors for the classification and grouping of the genus Pseudomonas. In these points, our experimental results of fatty acid composition analysis were incomplete in comparison with (Ikemoto et al.,1978), and the determination up to the species level was considered to be impossible in the present stage. But, it was concluded that Group VI is near to $M$. bovis and Group VII is near to P. caryophylli.

In conclusion, it was a very interesting result of 


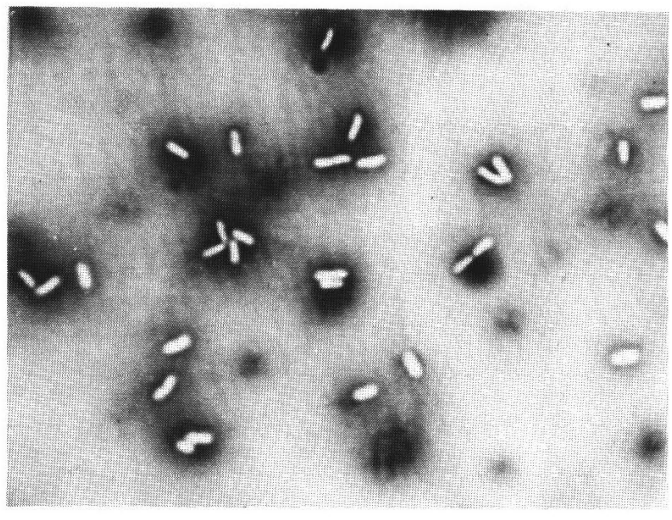

(a)

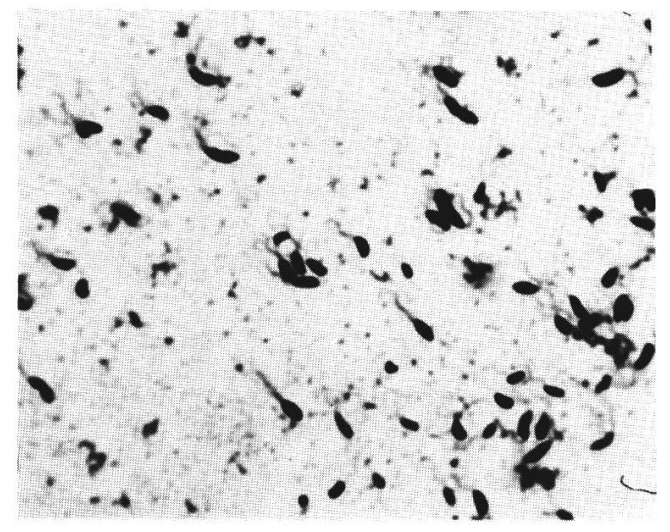

(b)

Fig. 5. (a) : Morphology of P-27 strain by negative stain. (b): Flagella of strain by Nishizawa and Sugawara method

our study that there was no obligate psychrophile but facultative psychrophile are abundant in tropical districts. These results were a new information of psychrophilic bacteria in such a tropical region as Indonesia.

\section{Acknowledgement}

All strains investigated were isolated by $\mathrm{Dr}$. Suhadi et al. (Parsar Jumat Res. Center in Indonesia) and Dr. Matuyama et al. (Institute of Physical and Chemical Research), to whom the authors are very much grateful. We also thank the late Dr. S. Okasawa for his kind and useful advices.

\section{References}

Buchanan, R.E. and N.E. Gibbons (ed.) 1974. Bergey's Manual of Determinative Bacteriology, 8th, ed., Williams and Willkins.

Cowan, S.T. and K.J. Steel, 1974. Identification of Medical Bacteria, 2nd ed., Cambridge University Press.

Doetsch, R.N. and T.M. Cook, 1973. Introduction to Bacteria and their Ecobacteriology. University Park Press, Batimore.

Ikemoto, S., H. Huraishi, K. Komagata, R. Azuma, T. Sato and H. Murooka, 1978. Cellar Fatty Acid Composition in Pseudomonas species. J. Gen. Appl. Microbiol., 24, 199-213.

Kaneko, I., H. Matsushima, A. Matsuyama, F. Suhadi and F. Kaneko, 1979. Proc. Ann. Meet. Agric. Soc. Jpn., p. 486. (in Japanese).

Nishimura, Y., H. Yamamoto and H. Iizuka, 1979. Taxonomical studies of Acinetobacter species - cellular fatty acid composition. Z. Allg. Mikrobiol., 19, 307-308.

Okasawa, S., H. lizuka, A. Matsuyama and F. Suhadi, 1980.

Proc, Ann. Meet. Agric. Soc. Jpn, p. 351, (in Japanese).

Stanier et al., 1966. The aerobic Pseudomonas; a taxonomic Study. J. Gen. Microbiol., 43, 159.

Suhadi, F., S.H. Thayib, M. Isnaeni, Harsojo, A. Matsuyama, Y. Hattori, S. Okasawa, I. Kaneko and S. Kitayama, 1977. Proc. Ann. Meet. Agric. Soc. Jpn., P. 249. (in Japanese).

Suhadi, F., S.H. Thayib, M. Isnaeni, Harsojo, Y. Hattori, S. Okasawa, I. Kneko, S. Kitayama, F. Kaneko and A. Matsuyama, 1979. Proc. Annu. Meet. Agric. Soc. Jpn., p. 486. (in Japanese).

Suhadi, F., S.H. Thayib, E.G. Siagian, M. Isnaeni, Harsojo, A. Matsuyama, F. Kaneko, I. Hattori, S. Okasawa, I. Kaneko and S. Kitayama, 1979. Proc. Ann. Meet. Agric. Soc. Jpn., p. 486. (in Japanese).

Tokyo Daigaku Nogakubu Nogeikagaku Kyoshitu, 1978. Nogeikagaku Jikenho. 3rd ed., Asakura Shoten.

(Received December 6, 1988-Accepted February 20, 1989) 